University of Nebraska - Lincoln

DigitalCommons@University of Nebraska - Lincoln

Faculty Publications: Department of

Entomology

$6-28-2021$

Impact of maize hormonal interactions on the performance of

Spodoptera frugiperda in plants infected with Clavibacter

michiganensis subsp. nebraskensis

Karen Da Silva

Sydney E. Everhart

Joe Louis

Follow this and additional works at: https://digitalcommons.unl.edu/entomologyfacpub

Part of the Entomology Commons

This Article is brought to you for free and open access by the Entomology, Department of at

DigitalCommons@University of Nebraska - Lincoln. It has been accepted for inclusion in Faculty Publications:

Department of Entomology by an authorized administrator of DigitalCommons@University of Nebraska - Lincoln. 


\title{
Impact of maize hormonal interactions on the performance of Spodoptera frugiperda in plants infected with Clavibacter michiganensis subsp. nebraskensis
}

\author{
Karen F. Da Silva, ${ }^{1,4}$ Sydney E. Everhart, ${ }^{1}$ and Joe Louis ${ }^{2,3}$
}

1 Department of Plant Pathology, University of Nebraska-Lincoln, 406 Plant Sciences Hall, Lincoln, NE 68583-0722, USA

2 Department of Entomology, University of Nebraska-Lincoln, 103 Entomology Hall, Lincoln, NE 68583-0816, USA

3 Department of Biochemistry, University of Nebraska-Lincoln, Lincoln, NE 68583, USA

4 Present Address: Corteva Agriscience, Woodland, CA 95695, USA

Email: Sydney E. Everhart everhart@unl.edu ; Joe Louis joelouis@unl.edu

ORCiD

Sydney E. Everhart http://orcid.org/0000-0002-5773-1280 Joe Louis http://orcid.org/0000-0001-7137-8797

\begin{abstract}
In nature, plants interact with multiple organisms, below and aboveground. Although interactions of plants with single biotic stressors are well characterized, knowledge of how the immune system responds to multiple biotic stressors is lacking. It is known that the two most important pathways involved in the plant immune defenses
\end{abstract}

Published in Arthropod-Plant Interactions 15 (2021), pp 699-706.

doi:10.1007/s11829-021-09849-x

Copyright (c) 2021 Karen F. Da Silva, Sydney E. Everhart, Joe Louis, under exclusive license

to Springer Nature B.V. Used by permission.

Submitted 9 March 2021; accepted 15 June 2021; published 28 June 2021. 
are jasmonic acid (JA) and salicylic acid (SA). The crosstalk between these plant hormonal signaling pathways seems to fine-tune the plant responses to different stressors. In this study, we characterized maize (Zea mays) hormonal interactions under the attack of two economically important pests: the bacterial pathogen that causes Goss's bacterial wilt and leaf blight (Clavibacter michiganensis subsp. nebraskensis), and the chewing insect, fall armyworm (Spodoptera frugiperda). Our results indicate that the Goss's wilt-resistant maize plants when pretreated with bacteria became more vulnerable to the subsequent attack by the fall armyworm larvae. Furthermore, plant hormone analysis demonstrated that the antagonistic interactions of JA-Isoleucine (JA-Ile), biologically active form of JA, and SA in maize plants contributed to enhanced plant susceptibility to herbivory. Collectively, our results suggest that plant hormonal interactions may play a major role in maize defense against multiple biotic stressors. Furthermore, this study will improve our understanding and ability to predict plant-induced hormone responses in an economically important crop.

Keywords: Fall armyworm, Goss's bacterial wilt and leaf blight, Maize, Phytohormones

\section{Introduction}

Plants are frequently challenged by various biotic stressors such as insect and vertebrate herbivores, and pathogens such as fungi, viruses, and bacteria. These attacks can occur either simultaneously or sequentially. In response to these stressors, plants have a multitude of defense mechanisms including constitutive and inducible defenses (Howe and Jander 2008; Louis and Shah 2013; Zust and Agrawal 2017; Erb and Reymond 2019). Constitutive defenses include both preformed physical barriers and chemical factors, whereas inducible defenses include the induction of signaling cascades, which consequently lead to the production of metabolites and/or plant hormones (Chen 2008; Howe and Jander 2008; Pieterse et al. 2012; Nalam et al. 2019). Unfortunately, knowledge of the molecular mechanisms underlying the interactions of multiple biotic stressors in the same plant species is lacking. This information is critical for development of host plants with robust host resistance that is stable under multiple biotic and abiotic stressors. Among the few studies evaluating multiple stressors on host plant response, it is suggested that response of the plant immune system and expression of plant hormonal signaling pathways depend on the mechanism feeding behavior/pathogen ingress (i.e., biotrophic/necrotrophic pathogens) (Thaler 
et al. 1999, 2010, 2012; Ali and Agrawal 2012; Moreira et al. 2018). The two most important hormonal signaling pathways associated with induced plant defenses are jasmonic acid (JA) and salicylic acid (SA). The crosstalk between these plant hormonal signaling pathways is a well-studied phenomenon, and it has been shown that expression of these hormones is correlated with negative or positive pest performance in plants, depending on the plant/pest system. However, very little information is available on the molecular mechanisms underlying the interactions of multiple biotic stressors in herbaceous monocot plants, including maize (Zea mays L.).

Clavibacter michiganensis subsp. nebraskensis (CMN) (Vidaver \& Mandel) and Spodoptera frugiperda (Smith) (Lepidoptera: Noctuidae) are important corn pests. CMN is a maize pathogen that has been historically confined to the U.S. Midwest. This gram-positive bacterium primarily infects maize plants through wounds caused by winddriven rain, hail, and other mechanical damage causing wilt and leaf blight symptoms. A recent study described the results of a survey of agronomic practices and other problems that occurred in fields from which samples tested positive for $\mathrm{CMN}$ and detected an effect in the bacterial infection by the presence of insects (Langemeier et al. 2017). When CMN infection occurs early during seedling stages, they can cause systemic vascular infections of their host plants and reside as biotrophic pathogens in the xylem vessels (Eichenlaub and Gartemann 2011). In addition, the bacteria can overwinter in crop residues (Jackson et al. 2007). Yields can be reduced up to $50 \%$ when susceptible hybrids are infected, and currently there is no commercial resistant maize hybrid available that provides complete protection against this pathogen (Claflin 1978; Jackson et al. 2007).

One threat to the existing plant host resistance to Goss's bacterial wilt disease is pest damage caused by an economically important phytophagous insect in maize, the fall armyworm (FAW), S. frugiperda. FAW is an important pest in maize that has spread through North and South America, and as an invading species in Africa, and more recently in Asia (Montezano et al. 2018; Ganiger et al. 2018). Currently, the management practice to control this pest is the use of resistant hybrids expressing insecticidal protein from the bacterium Bacillus thuringiensis (Bt). Unfortunately, there is an increasing number of field-evolved reports of resistance in this insect to $B t$ transgenic traits (Tabashnik and Carriere 2017). 
It is unknown whether interactions between plant hormonal signaling pathways can be correlated with negative or positive pest performance in maize under the subsequent damages from chewing insects and biotrophic pathogens. A recent study with CMN and parental lines of the maize nested association mapping (NAM) population showed variable levels of resistance to CMN (Hu et al. 2018). In this study, we used the maize NAM founder lines, B73 and Oh7B, that were identified as moderately resistant and susceptible lines, respectively, against CMN (Hu et al. 2018). We further explored how initial infection by the biotrophic pathogen CMN on B73 and Oh7B lines will influence the subsequent attack by a different biotic stressor, a chewing insect. Our results indicate that there is resistance trade-off based on the antagonistic effects between JA-isoleucine (JA-Ile), biologically active form of JA (Howe and Jander 2008), and SA so that infection by Goss's bacterial wilt and leaf blight reflects in the increase of plant susceptibility to subsequent attack by FAW. Understanding the interactions among plant-bacterium-chewing insect can contribute to our comprehension of ecosystem processes and ability to predict the outcome of plantmediated interactions.

\section{Materials and methods}

\section{Bacteria and insects}

A strain of the Goss's bacterial wilt and leaf blight pathogen, CMN 225A, was collected from a symptomatic corn sample collected from Nebraska in 2011 as part of a multistate survey across the Midwest (Langemeier et al. 2017) and used in these experiments. This bacterial strain was selected for this study due to its known virulence or aggressiveness in maize studies. This strain has been in culture at the University of Nebraska-Lincoln in a nutrient broth yeast agar (NYB) solid medium and maintained at room temperature for 2 days before inoculation. As a subsequent attacker, newly hatched (for bioassay) and third instar (for phytohormone analysis) larvae of FAW were used to infest maize plants inoculated with CMN. FAW larvae were obtained from a commercial vendor (Benzon Research Inc., PA) on an artificial diet, and were kept at room temperature prior to infestation. 


\section{Plant lines and growth conditions}

Two NAM founder lines B73 and Oh7B were selected based on their level of resistance to the bacterial pathogen (Hu et al. 2018) and were identified as moderately resistant and susceptible lines, respectively. Both lines were obtained from the U.S. National Plant Germplasm System (USDA Agricultural Research Station, Ames, IA). Plants were grown in all-purpose growing mix Berger BM6 (Hummert International, Earth City, MO), in the Agronomy and Horticulture glasshouse at the University of Nebraska-Lincoln. These plants were grown in $3.8 \mathrm{~cm} \times 21$ $\mathrm{cm}$ plastic cone-tainers (Hummert International, Earth City, MO). The glasshouse environmental setting was 14-h/10-h (light/dark) photoperiod, $25-27{ }^{\circ} \mathrm{C}$, and 50 to $60 \%$ relative humidity. All plants for the experiments were used at V3 developmental stage or approximately 2-3 weeks from planting. These aforementioned conditions were applied to address the following research objectives to identify how the initial infection by the biotrophic pathogen CMN on B73 and Oh7B lines will influence the subsequent attack by the chewing insect, FAW, and to further identify the molecular mechanisms involved in maize response to these biotic interactions.

\section{Insect performance after bacterial pretreatment in maize plants assay}

The bacterial suspension consisted of a combination of CMN cells scraped from media plates and eluted into sterile distilled water. The concentration of the suspension obtained for infection was adjusted to a concentration of $3 \times 10^{9} \mathrm{CFU} / \mathrm{ml}$, which was used in previous experiments to evaluate symptom development in maize. Plant inoculations were performed by slowly injecting $100 \mu \mathrm{l}$ of the bacterial suspension into the maize stem interspace between the first and second leaf, using $1 \mathrm{ml}$ syringe with 28 gauge and $12.7 \mathrm{~mm}$ needle (BD Allergy Syringe). Negative control plants were injected with the same volume of water only and non-inoculated control plants received no injection. Inoculations were performed in the evening and $15 \mathrm{~h}$ later, a single FAW neonate larva was transferred to the whorl of each plant. The 15 h-mark was selected based on results of a previous QTL study for resistance to Goss's bacterial wilt and leaf blight (Singh et al. 2019). The 
pathogen responsive genes $P R 1$ and $P R 5$, commonly used molecular markers of SA, were expressed within 12 to $15 \mathrm{~h}$ after CMN inoculation (Singh et al. 2019). To avoid larval escape, single pot was covered with a plastic cage. The weight of individual larva was measured after 7 days of infestation. There were thirteen biological replications for each treatment (i.e., plants inoculated with a bacterial suspension, negative control plants inoculated with water only, and non-inoculated control plants). These experiments were conducted twice with similar results.

\section{Bacteria and insect interaction for hormone quantification}

To characterize phytohormone response under multiple biotic stressors, plants were inoculated/infested in the same manner as described above, followed by phytohormone quantification. For hormone quantification, the same methodology as described previously was used (Varsani et al. 2019; Grover et al. 2020). However, plant samples were collected at two different time points. The first time was $15 \mathrm{~h}$ after bacterial/distilled water inoculation and the second time was $24 \mathrm{~h}$ after FAW larvae infestation. Plant samples consisted of approximately $2 \mathrm{~cm}$ length of the upper stem area, closer to the whorl, and weighing 100-150 mg. The remaining plants were infested with single third instar FAW larva, placed directly in the whorl of the plant. Third instar larvae were used in this experiment as they are in an advanced stage of development and could begin feeding on the plant within a short period of time. Larvae were allowed to feed for $24 \mathrm{~h}$, and then plant tissue sampling was repeated at the same plant area and weight. Each treatment had three to five biological replications depending on sample availability. Maize tissues were ground using a 2010 Geno/Grinder (SPEX SamplePrep) for 40 $\mathrm{s}$ at 1400 strokes $\mathrm{min}^{-1}$ with liquid nitrogen cooling to keep samples frozen throughout the grinding process. Samples were delivered on dry ice to the Proteomics and Metabolomics Facility at the University of Nebraska-Lincoln for targeted quantification of phytohormones using liquid chromatography-MS/MS, as described previously (Varsani et al. 2019; Grover et al. 2020). 


\section{Statistical analysis}

Experimental units were a complete factorial arranged in a completely randomized design. Two-way analysis of variance (ANOVA) was conducted with PROC GLIMMIX (SAS 9.4, SAS Institute) to evaluate the effect of plant line, treatment, and interactions between plant variety and bacterial pretreatment on fall armyworm performance after bacterial pretreatment and hormonal quantification. When a significant difference was identified, a post hoc analysis using a Tukey's HSD pairwise comparison was performed to determine where significant differences lie among treatment means. Values from the interactions and from least-squares means of the treatments with $P \leq 0.05$ were considered to be significantly different.

\section{Results}

\section{Insect performance after bacterial pretreatment in maize plants}

There was an overall treatment effect $(P=0.0034)$ and treatment by maize genotype effect $(P=0.039)$ in the mean larval group weight. There was an increase of FAW weight in B73 maize plants that were pretreated with $\mathrm{CMN}$. While the mean larval group weight followed by standard error value in $\mathrm{CMN}$-pretreated B73 plants was $86.29 \pm$ $7.81 \mathrm{mg}(P<0.0001)$, the mean weight from larvae that fed on plants pretreated with water was only $59.38 \pm 3.71 \mathrm{mg}(P<0.0001)$. FAW from uninfected plants (control plants) had an average weight of 68.15 $\pm 3.61 \mathrm{mg}(P<0.0001 ;$ Fig. 1$)$. The FAW weight between CMN-pretreated plants between genotypes was significantly different $(P=$ $0.0146)$. There was also a maize genotype effect observed in this study $(P=0.0213)$. In the susceptible line Oh7B, the mean larval weight from plants pretreated with $\mathrm{CMN}$ was $65.46 \pm 3.42 \mathrm{mg}(P<0.0001)$. The mean larval group weight from negative control plants that were inoculated with water and the non-inoculated control plants were 61.46 \pm 3.27 , and $60.62 \pm 2.93 \mathrm{mg}$, respectively. 


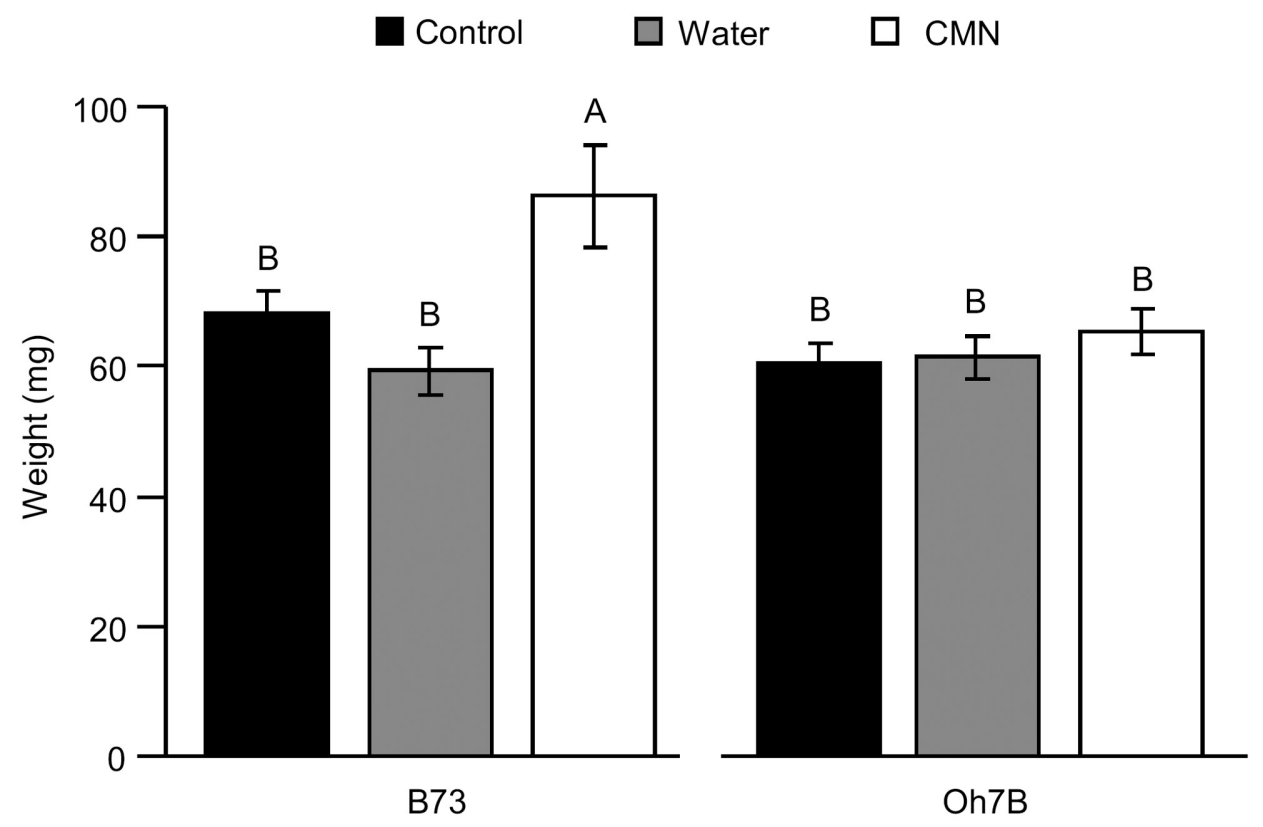

Figure 1 Fall armyworm (Spodoptera frugiperda) performance after bacterial pretreatment in maize plants. Fall armyworm (FAW) weight increased in plants treated with Clavibacter michiganensis subsp. nebraskensis (CMN), causal agent of Goss's bacterial wilt and leaf blight. Moderately resistant (B73) and susceptible (Oh7B) lines were pretreated with either a CMN suspension or water only. Control plants did not receive bacterial pretreatment; water was used as negative control. After $15 \mathrm{~h}$ post inoculation, single FAW neonate was transferred to the whorl of each plant. FAW weight was measured after 7 days of feeding. Different letters indicate significant difference between treatments $(P \leq 0.05)$. Error bars represent \pm SEM

\section{Bacteria and insect interaction for hormone quantification}

To characterize if the difference in performance of FAW in bacterial pretreated plants is due to SA and JA-mediated responses, maize plant samples were analyzed for hormone concentrations. The levels of JAIle, the biologically active form of JA (Howe and Jander 2008), were not altered in both B73 and Oh7B maize plants after $15 \mathrm{~h}$ of CMN inoculation (Fig. 2A). However, SA accumulation was significantly increased in CMN-resistant B73 plants $15 \mathrm{~h}$ post inoculation (hpi) of CMN (Fig. 2B). We did not find any significant difference in the levels of SA with and without CMN inoculation on Oh7B plants after 15 hpi (Fig. 2B). 
A

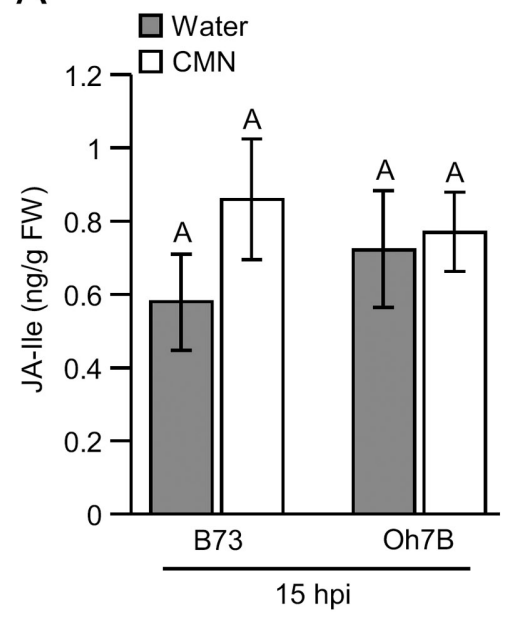

B

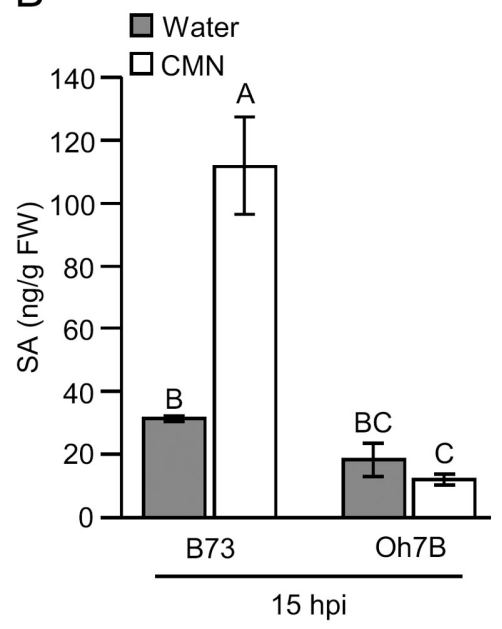

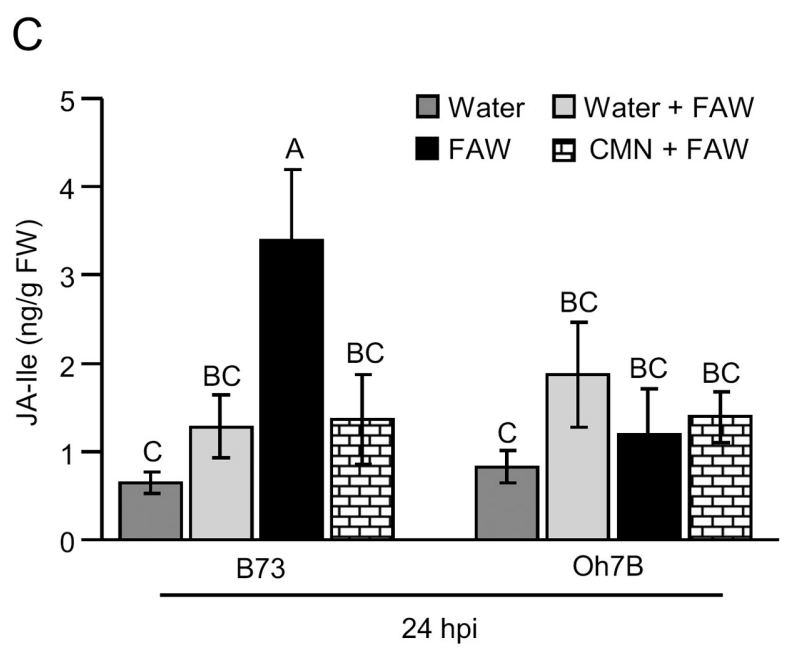

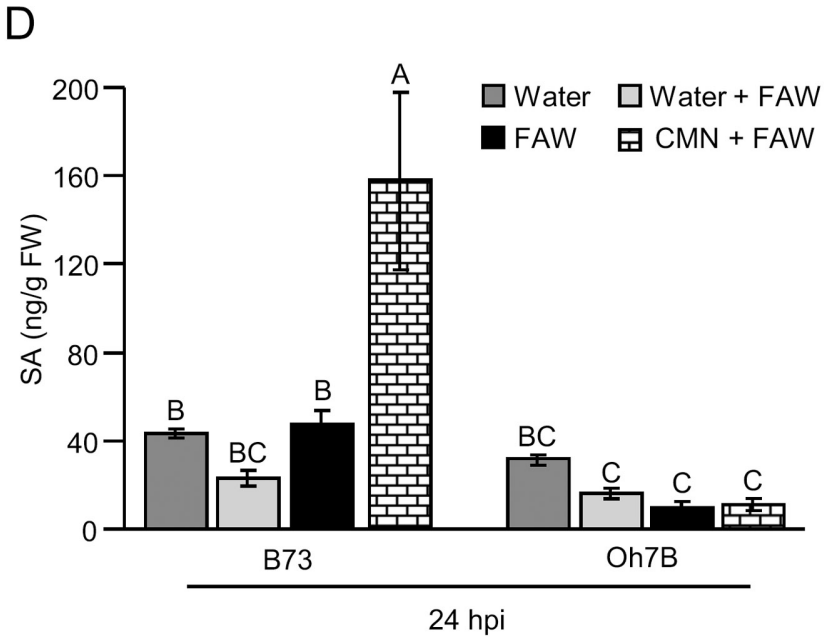

Figure 2 Maize hormonal response to co-infection/infestation of Clavibacter michiganensis subsp. nebraskensis and fall armyworm (Spodoptera frugiperda). Levels of $\mathbf{A}$ jasmonic acid-isoleucine (JA-lle) and $\mathbf{B}$ salicylic acid (SA) in B73 and Oh7B plants that were inoculated with either water or a bacterial suspension of Clavibacter michiganensis subsp. nebraskensis (CMN) for $15 \mathrm{~h}$. Levels of C JA-Ile and D SA in B73 and Oh7B plants that were pretreated with water, water plus fall armyworm (FAW), FAW alone, and CMN followed by FAW feeding for $24 \mathrm{~h}$. $F W$ fresh weight. Different letters indicate significant difference between treatments $(P \leq 0.05)$. Error bars represent \pm SEM 
We also measured the levels of JA-lle and SA on both B73 and Oh7B plants after pretreating the maize plants with CMN for $15 \mathrm{~h}$ followed by FAW infestation for $24 \mathrm{~h}$. FAW feeding for $24 \mathrm{~h}$ on B73 plants triggered the accumulation of JA-Ile compared to water-inoculated B73 control plants (Fig. 2C). Surprisingly, we also found that B73 plants that were pre-inoculated with water followed by FAW infestation had significantly lower levels of JA-Ile compared to B73 plants that were infested with FAW alone. Because the water plus FAW infestation did not exhibit similar significant increase in JA-lle compared to FAW feeding alone on B73 plants, these data should be treated with caution. Water inoculation on B73 plants may have resulted in an earlier accumulation of JA-Ile, which was no longer detectable at the timepoints that was chosen for this experiment (i.e., $24 \mathrm{~h}$ after FAW infestation). Alternatively, the injection of water with needle on B73 plants may have trigged the SA accumulation that contributed to reduced accumulation of JA-lle after 24 of FAW feeding. However, this is less likely, because we observed no significant differences in SA levels in B73 plants after water inoculation and with and without FAW feeding (Fig. 2D). Compared with the FAW feeding alone, we found a significant decrease in the levels of JA-Ile on CMN-resistant B73 plants that were exposed to the combination of CMN and FAW infestation (Fig. 2C). No significant changes were found in the levels of JA-lle in the CMN-susceptible Oh7B plants with and without CMN pretreatment and FAW feeding for $24 \mathrm{~h}$ (Fig. 2C). Similarly, no significant differences were found in the levels of SA in the Oh7B plants with and without CMN pretreatment and FAW feeding for $24 \mathrm{~h}$ (Fig. 2D). In addition, there were no significant changes in the SA levels in the CMN-resistant B73 plants with and without water inoculation followed by FAW feeding for $24 \mathrm{~h}$ (Fig. 2D). However, CMN-resistant maize B73 plants exposed to the combination of CMN and FAW feeding for $24 \mathrm{~h}$ exhibited significant increase in SA levels compared to plants that were treated with water alone, water plus FAW, and FAW alone (Fig. 2D).

\section{Discussion}

Plants encounter various biotic stressors; however, very little is known about how these interactions play out in the ecosystem and whether 
co-infection modifies plant resistance or susceptibility. Broadly, knowledge on host response to interactions involving insects and pathogens is lacking. This is the first study on maize using tri-partite interaction assays between biotrophic pathogens and chewing herbivores. Our results showed that inoculation of $C M N$ increased weight of the subsequent attacker FAW in the maize B73 line. In Bacher et al. (2002), females of the boring weevil, Apion onopordi, showed enhanced performance in weed creeping thistle plants, Cirsium arvense, pretreated with the biotrophic rust fungus, Puccinia punctiformis. In contrast, Brassica nigra plants that were pretreated with either egg extract from a chewing herbivore, Pieris brassicae, or the biotrophic bacterium, Xanthomonas campestris, had a negative impact on the herbivore growth (Bonnet et al. 2017). However, there was no attempt to elucidate the plant defense mechanism(s) that could explain these results.

In the present study, we further explored the hormonal mechanism that maize plants use against combined biotic stressors. JA and SA are mainly known to play major roles in regulating plant defense responses against pathogens and insects (Pieterse et al. 2012). Biotrophic pathogens and some piercing/sucking insects, generally induce SA signaling accompanied by the production of pathogenesis-related (PR) proteins, whereas JA-mediated responses are predominantly against necrotrophic pathogens and chewing insects (Thaler et al. 2012). Maize hormonal profiling in this study suggests that the induction of plant defense responses after CMN infiltration is correlated with the induction of SA and the infestation of FAW with the induction of JA-Ile in the CMN-resistant maize line (B73; Fig. 2).

Characterizing both susceptible and resistant lines in these types of multi-pest-pathogen interaction studies provide insight into how changes in secondary pest performance may be related to primary pest-induced changes in plant susceptibility. In maize, we demonstrated that increased pest performance was due to differences in the host plant genetic variability and related to differences in the induction of SA hormone levels between the resistant and susceptible maize plants to CMN. Previously, it was shown that SA-responsive transcripts tend to accumulate quicker and to higher levels in leaves of resistant plants than in susceptible plants (Martinez de llarduya et al. 2003). Similarly, our results indicated that CMN-resistant maize plants had elevated levels of SA compared to susceptible plants (Fig. 
2B). As different maize varieties are genetically distinct, it would be useful for future studies to evaluate interactions in additional maize genotypes to determine if these changes in pest susceptibility correlate with hormone levels.

In nature, plants are likely to experience multiple biotic stresses that elicit phytohormonal responses interacting to yield a synergistic or antagonistic effect that may ultimately shape the plant phenotype and/or resistance. However, evidence of reciprocal antagonism reported in studies measuring molecular aspects of the host response might not be reflective of all species of herbivores and pathogens (Moreira et al. 2018). Results presented in this study suggest that the CMN infection followed by FAW herbivory can affect maize JA and SA-induced pathways antagonistically. While levels of JA-lle increased in FAW treatment alone, they did not change upon CMN infection and the sequential attack of FAW. Meanwhile, concentration of SA increased significantly under combination of FAW and CMN treatments when compared to CMN alone (Fig. 2). The increase in SA concentration levels could cause the suppression of JA-lle levels resulting in the increase of plant susceptibility to chewing herbivores. Indeed, it was previously shown that application of exogenous SA and its functional analogs, such as aspirin, 2,6-dichloroisonicotinic acid (INA), activates expression of PR genes (Uknes et al. 1992; White 1979), and blocks the JA signaling process (Doherty et al. 1988; Pena-Cortes et al. 1993), suggesting that crosstalk between JA and SA could exist. Interestingly, Engelberth et al. (2011) proposed that the SA-JA antagonism is absent in maize. In that study, insect elicitor-induced JA was more than two-fold upregulated in exogenous SA-pretreated maize plants. Using artificial elicitors is an alternative to test plant responses; however, it does not take into consideration the wide range of elicitors produced by multiple stressors (e.g., co-infection by bacteria and insects) that consequently interfere with the plant immune response.

One of the factors that can interfere in the reproducibility of types of assays is that the antagonism between JA and SA depends on the concentration and timing of elicitation of each pathway (Thaler et al. 2002). To provide more complete picture of the hormone mechanism in these assays, it would be important to test these pest interactions and the phytohormone levels at different time points and plant developmental stages. Additionally, it would be important to extend 
these types of studies in other environmental conditions. Similar to other interaction studies, these assays were conducted in semi-controlled environments where maize plants were in early stages and exposed to controlled delivery of disease inoculum volume. Calub et al. (1974) indicated that inoculation timings performed on 2-week-old seedlings routinely resulted in increased disease severity to Goss's bacterial wilt and leaf blight compared to inoculations performed on older seedlings. However, when a resistant hybrid was used, inoculation timing had little impact on either disease severity or yield. Furthermore, in other less controlled environments, such as in the field, other factors (e.g., abiotic factors) may also play a role in modulating plant defenses (Liu et al. 2013; Riemann et al. 2015). It is well known that these phytohormones can be elicited under poor environmental conditions as well, such as drought. JA, in particular, can also be involved with other volatile compounds such as ethylene, for instance, under nitrogen deficiency (Schmelz et al. 2003). Taken together, these studies suggest that external factors can also contribute to a greater variation of hormone production under natural conditions and can ultimately indirectly promote variation in plant susceptibility to pests.

Finally, the results of this study are relevant to growers and seed producers. For growers, it is important to scout the field early to the presence of Goss's bacterial wilt and leaf blight symptoms. For seed producers, the presence of secondary pests can impact the durability of the resistance used in the field. Evaluating parental lines that are commonly used in the background for generation of maize hybrids, to a potential secondary pest attack, especially those pests that have a significant ecological presence in the area, can benefit the long-term efficacy of the technology.

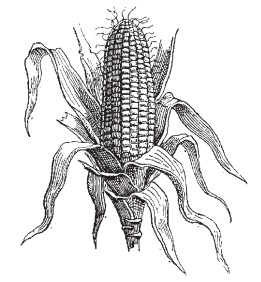


Acknowledgments We thank members of Everhart and Louis labs for their help with experiments and the Proteomic and Metabolomics Facility (Center for Biotechnology at the University of Nebraska-Lincoln) for the LC-MS assay and quantification of plant hormones. We also thank Drs. Tamra Jackson-Ziems and Ana Maria Velez for comments on the draft of the article. This work was supported by funds from Agricultural Research Division and Department of Plant Pathology at the University of Nebraska-Lincoln.

Author contributions KFDS, SEE and JL conceived and designed the research; KFDS performed the research; KFDS, SEE and JL analyzed the data; KFDS wrote the first draft of the manuscript and all authors reviewed and edited the manuscript.

Funding Agricultural Research Division and Department of Plant Pathology at the University of Nebraska-Lincoln.

Data availability Datasets generated and/or analyzed during the current study are available from the corresponding authors on reasonable request.

Conflict of interest The authors have no conflicts of interest to declare.

\section{References}

Ali JG, Agrawal AA (2012) Specialist versus generalist insect herbivores and plant defense. Trends Plant Sci 17:293-302

Bacher S, Friedli J, Schar I (2002) Developing in diseased host plants increases survival and fecundity in a stem-boring weevil. Entomol Exp Appl 103:191-195

Bonnet C, Lassueur S, Ponzio C, Gols R, Dicke M, Reymond P (2017) Combined biotic stresses trigger similar transcriptomic responses but contrasting resistance against a chewing herbivore in Brassica nigra. BMC Plant Biol 17:127

Chen MS (2008) Inducible direct plant defense against insect herbivores: a review. Insect Sci 15(2):101-114

Claflin LE, Bockelman DL, Shahin EA, Walter TL (1978) The effect of Corynebacterium nebraskense on corn yields. Phytopathol News 12:86

Doherty HM, Selvendran RR, Bowles DJ (1988) The wound response of tomato plants can be inhibited by aspirin and related hydroxybenzoic acids. Physiol Mol Plant Pathol 33:377-384

Eichenlaub R, Gartemann K-H (2011) The Clavibacter michiganensis subspecies: molecular investigation of gram-positive bacterial plant pathogens. Annu Rev Phytopathol 49:445-464

Engelberth J, Viswanathan S, Engelberth MJ (2011) Low concentrations of salicylic acid stimulate insect elicitor responses in Zea mays seedlings. J Chem Ecol 37:263-266

Erb M, Reymond P (2019) Molecular interactions between plants and insect herbivores. Annu Rev Plant Biol 70:527-557 
Ganiger PC, Yeshwant HM, Muralimohan K, Vinay N, Kumar ARV, Chandrashekara K (2018) Occurrence of the new invasive pest, fall armyworm, Spodoptera frugiperda (J.E. Smith) (Lepidoptera: Noctuidae), in the maize fields of Karnataka. India. Curr Sci 115:621-623

Grover S, Agpawa E, Sarath G, Sattler SE, Louis J (2020) Interplay of phytohormones facilitate sorghum tolerance to aphids. Plant Mol Biol. https:// doi. org/ 10. 1007/ s11103- 020- 01083-y Howe GA, Jander G (2008) Plant immunity to insect herbivores. Annu Rev Plant Biol 59:41-66

Hu Y, Ren J, Peng Z, Umana AA, Le H, Danilova T, Fu J, Wang H, Robertson A, Hulbert SH, White FF, Liu S (2018) Analysis of extreme phenotype bulk copy number variation (XP-CNV) identified the association of rp1 with resistance to Goss's wilt of maize. Front Plant Sci 9:110

Jackson TA, Harveson RM, Vidaver AK (2007) Reemergence of Goss's wilt and blight of corn to the central high plains. Plant Health Prog 8:44

Langemeier CB, Robertson AE, Wang D, Jackson-Ziems TA, Kruger GR (2017) Factors affecting the development and severity of Goss's bacterial wilt and leaf blight of corn, caused by Clavibacter michiganensis subsp. nebraskensis. Plant Dis 101(1):54-61

Liu P, Xu Z-S, Pan-Pan L, Hu D, Chen M, Li L-C, Ma Y-Z (2013) A wheat PI4K gene whose product possesses threonine autophophorylation activity confers tolerance to drought and salt in Arabidopsis. J Exp Bot 64:2915-2927

Louis J, Shah J (2013) Arabidopsis thaliana-Myzus persicae interaction: shaping the understanding of plant defense against phloem-feeding aphids. Front Plant Sci 4:213

Martinez de Ilarduya O, Xie Q, Kaloshian I (2003) Aphid-induced defense responses in $\mathrm{Mi}$-1-mediated compatible and incompatible tomato interactions. Mol Plant-Microbe Interact MPMI 16:699-708

Montezano DG, Specht A, Sosa-Gomez DR, Roque-Specht VF, Sousa-Silva JC, Paula-Moraes SV, Peterson JA, Hunt TE (2018) Host plants of Spodoptera frugiperda (Lepidoptera: Noctuidae) in the Americas. Afr Entomol 26:286-300

Moreira X, Abdala-Roberts L, Castagneyrol B (2018) Interactions between plant defence signalling pathways: evidence from bioassays with insect herbivores and plant pathogens. J Ecol 106:2353-2364

Nalam VJ, Louis J, Shah J (2019) Plant defense against aphids, the pest extraordinaire. Plant Sci 279:96-107

Pena-Cortes H, Albrecht T, Prat S, Weiler EW, Willmitzer L (1993) Aspirin prevents wound-induced gene expression in tomato leaves by blocking jasmonic acid biosynthesis. Planta 191:123-128

Pieterse CMJ, Van der Does D, Zamioudis C, Leon-Reyes A, Van Wees SCM (2012) Hormonal modulation of plant immunity. Annu Rev Cell Dev Biol 28:489-521

Riemann M, Dhakarey R, Hazman M, Miro B, Kohli A, Nick P (2015) Exploring jasmonates in the hormonal network of drought and salinity responses. Front Plant Sci. https://doi.org/10.3389/fpls.2015.01077 
Schmelz EA, Alborn HT, Engelberth J, Tumlinson JH (2003) Nitrogen deficiency increases volicitin-induced volatile emission, jasmonic acid accumulation, and ethylene sensitivity in maize. Plant Physiol 133:295-306

Singh A, Li G, Brohammer AB, Jarquin D, Hirsch CN, Alfano JR, Lorenz AJ (2019) Genome-wide association and gene co-expression network analyses reveal complex genetics of resistance to Goss's wilt of maize. G3 Genes Genomes Genet 9:3139-3152

Tabashnik BE, Carriere $Y$ (2017) Surge in insect resistance to transgenic crops and prospects for sustainability. Nat Biotechnol 35:926-935

Thaler JS, Fidantsef AL, Duffey SS, Bostock RM (1999) Trade-offs in plant defense against pathogens and herbivores: a field demonstration of chemical elicitors of induced resistance. J Chem Ecol 25:1597-1609

Thaler JS, Fidantsef AL, Bostock RM (2002) Antagonism between jasmonate- and salicylate-mediated induced plant resistance: effects of concentration and timing of elicitation on defense-related proteins, herbivore, and pathogen performance in tomato. J Chem Ecol 28:1131-1159

Thaler JS, Agrawal AA, Halitschke R (2010) Salicylate-mediated interactions between pathogens and herbivores. Ecology 91:1075-1082

Thaler JS, Humphrey PT, Whiteman NK (2012) Evolution of jasmonate and salicylate signal crosstalk. Trends Plant Sci 17:260-270

Uknes S, Mauch-Mani B, Moyer M, Potter S, Williams S, Dincher S, Chandler D, Slusarenko A, Ward E, Ryals J (1992) Acquired resistance in Arabidopsis. Plant Cell 4:645-656

Varsani S, Grover S, Zhou S, Koch KG, Huang P-C, Kolomiets MV, Williams WP, Heng-Moss T, Sarath G, Luthe DS, Jander G, Louis J (2019) 12-Oxophytodienoic acid acts as a regulator of maize defense against corn leaf aphid. Plant Physiol 179:1402-1415

White RF (1979) Acetylsalicylic acid (aspirin) induces resistance to tobacco mosaic virus in tobacco. Virology 99:410-412

Zust T, Agrawal AA (2017) Trade-offs between plant growth and defense against insect herbivory: an emerging mechanistic synthesis. Ann Rev Plant Biol 68:513-534 